Lo Bianco, Joseph (2007). Contrasting and Comparing Minority Language Policy: Europe and

Australia. In Pauwels, A., Winter, J. and Lo Bianco, J. (eds) Maintaining Minority Languages in

Transnational Contexts (pp. 78-104). Basingstoke: Palgrave Macmillan. DOI:

10.1057/9780230206397, reproduced with permission of Palgrave Macmillan.

This extract is taken from the author's original manuscript and has not been edited. The definitive, published, version of record is available here: http://www.palgrave.com/gp/book/9780230019195

\title{
Contrasting and Comparing Minority Language Policy: Europe and Australia
}

\author{
Joseph Lo Bianco \\ The University of Melbourne
}

\section{Introduction}

Contrasting and comparing European and Australian practices in language maintenance is a problematic exercise. For a start, the constitutional parameters are different. Australia is a single sovereign national state, while 'Europe' is an aggregating entity, expanding from an economic treaty among six sovereign national states unsteadily towards pooled sovereignty at a supra-national level. Europe's moves towards political union, albeit hesitant and contested, give the appearance of reenacting the cultural policies of its member states (utilizing the state discourses of efficiency of communication, common citizenship, participation and democracy). However, at least rhetorically, and in some clear ways practically too, the emergent Europe differs considerably in its cultural policies from those enacted by its own member states.

One of the points of difference is in the treatment of minority languages. Political and juridical characteristics account for a significant part of the contrast that can be identified today between Australia and Europe in how minority languages are treated. The very process of negotiating the formation of the European Union (EU) and the subsequent work of the European bureaucracies that have emerged as European engagement has widened and deepened, from 6 to 25 states, from trade regulation to a quasi-state that talks of continental citizenship, has itself forced change onto the policies of individual European countries in relation to minority language policy. Here there is little basis for comparison, but rather for contrast, because Australia is not enmeshed in similar processes. However, two broad factors, globalization and the shared Europeanist ideology of one nation-one language, constitute grounds for comparison between Australian and individual European practices of language planning in relation to minority languages.

\section{Defining terms}

To begin discussing these issues it will help to define some basic terms. The most important pair is the nation-state combination. States can be formed from many contributing elements, the most important one for present purposes is the linking of nationality with statehood, in what is called here a national state. Family dynasties, religion and other bases for state formation have been common in the past and are found today, but most states make some claim to nationality as the basis of their formation.

Nation and state are terms whose common meanings almost totally contradict the technical meanings of these words. In popular under- standing, at least in English, people use the term nation for what scholars of nationalism usually prefer to call a state. The term state is less often misrecognized between its technical and popular meanings, but suffers from multiple meanings.

In this chapter (drawing on Enloe, 1981), the term nation refers to feelings of identity, interpersonal attachments and public sentiment, that is to the psychology of belonging and mutual loyalty. State by 
contrast refers to the activity of administration and formal authority.

In Enloe (1981) these two realms, identity and authority, are represented as two axes aligned vertically and horizontally, at whose intersection the specific characteristics of an individual national state can be determined. According to Enloe (1981, p. 123), 'The state is a vertical structure of public authority, in contrast with the nation, which is essentially a horizontal network of trust and identity'. Distinguishing between nation and state in this way allows us to discuss and better understand the relation between multilingual sociologies, in the horizontal domain, and the practices of public authorities in the vertical. The nation axis makes use of discourses and attachments of belonging together for groups of people who share the same geo-political space, but this is also a space of linguistic diversity, whereas the state typically insists on unity, efficiency and authority and has the means to enforce its choices.

Using this definition it is clear that 'Europe', meaning here the EU, is far from being a national state, because its vertical axis is comprised of the ceding or pooling of state authority from existing national states whose own responses to linguistic pluralism are very different.

Effective comparison of minority language treatment requires attention to the context of policy making and this, in turn, requires attention to the motivating force of these policies, which is the clear association of languages with nationalism. The European experience of nationalism has been particularly attentive to the ideology of exclusive national languages, selected, codified and given juridical primacy and cultural prominence, an experience and an ideology transferred to Australia as a Europeanized state. Both economic globalization and the supra-national structure of the EU are impacting deeply and often in ambiguous ways on this residual nationalist structure and its view of languages, evident in the different policy settings for various categories of minority or non-official languages.

\section{Nationalism}

National feeling, consciousness, loyalty and identity are items of meaning here contained under the overarching term nationalism. In the present analysis, nationalism is distinguished from patriotism and chauvinism, the former expressing a milder form of what the term nationalism conveys, the latter a more extreme form. Nationalism theory is usually seen to separate along a basic divide: some nationalities are seen to be primarily ethnic in origin and character, others to be primarily civic in origin and character.

Many nationalism scholars see civic nationalisms as a classification analogous to a political or Western variant and identify a separate blood-ancestry variant as an Eastern, cultural and sometimes a 'peripheral' nationalism. An elaborate formulation along these lines is offered by Greenfeld (1992) who distinguishes the ethnic and civic variants according to their origins and their present characteristics. In this analysis, political sovereignty as a social compact of free and equal individuals is an original nationalism, an English innovation, individualistic and civic in character. Although it is historically the first nationalism, Greenfeld argues that individualistic and civic nationalism is the rarest kind and is today virtually synonymous with Western liberal democratic polities. In this construction, the individual is an autonomous entity capable of volition and agency.

Contrasted with this individualistic and civic nationalism is a more common form of nationalism in which individuals form a 'composite entity' in nations imagined as a 'collective individual'. In this second kind of nationalism, political will resides with the collective, and this collective individual has its own distinctive interest independent of the human individuals that make it up. The interests of the collective individual take priority over separate human individuals. For Greenfeld, this second kind of nationalism is often tyrannical or at least it favours populist democracy and even socialism. However, some kinds of collectivist nations are also civic, France being the classic case; representing a collectivistic and civic type. This is historically the second type of nationalism to evolve. There is a 
tension at the heart of this kind of nationalism, according to Greenfeld, because its civic character defends individual freedom while its collectivistic dimension denies this freedom and as a result this kind of nation is plagued with problems and ambivalence, noted by Greenfeld (1992) as the 'turbulent political history' of the French nation.

The third and last type of nation to appear developed in Russia and Germany and is anti-western in character and the most common type in the world today. This third type combines a collectivistic definition of the nation with ethnic criteria of nationality.

Other nationalism theorizing, such as that of Hastings (1997), attributes historical primacy to the English nation seeing in its emergence the birth both of 'the nations' and indeed of nationalism. For Greenfeld, it was the upwardly mobile commoners of England in the sixteenth century who were critical in this process, as they were new Tudor aristocrats with an interest in re-defining the nation as one where upward mobility was permitted and possible and not constrained by aristocratic privilege. Hastings traces this further back, arguing that national feeling was 'detectable' in Saxon England, surviving the Norman Conquest of 1066, and growing in strength to emerge more powerfully with a vernacular literary creation and then be re-employed in through imperial expansion in America and elsewhere (Hastings, 1997, pp. 2-5). Without entering into the merits of these claims, these three types of nationalism evolve and emerge differently. Individualistic and civic-oriented nationalism is seen to respond to appeals that nationalism should serve the interests of upwardly mobile sections of the population. Collectivist nationalisms emerge when the social or economic basis of nationalism is restricted. As such, collectivism is seen to serve the interests of narrow elites as they seek power or status within narrow social frameworks, and they then transmit this nationalism, usually by indoctrination, to the masses. The first nationalism is civic, but collectivism as a basis for national state formation can develop a civic character, over time as it opens up to new members. Staying within the European framework the geographic distribution of these kinds of nationalism is as follows (Table 5.1):

Table 5.1 Kinds of nationalism in Europe: A geographic distribution

\begin{tabular}{ll}
\hline England & Individualistic and Civic Nationalism \\
France & Collectivistic and Civic Nationalism \\
Russia and Germany & Collectivistic and Ethnic Nationalism \\
\hline
\end{tabular}

Ethnic ideologies stress cultural similarity of particular groups, nationalism stresses the cultural similarity of its adherents. An implication of both terms is that boundaries are drawn vis-à-vis others, constituted by definition as outsiders. While ethnicity and nationalism share this quality, nationalism carries the specific additional element of implying a relationship with a state. The relation of ethnicity to nationalism depends on the intervening role of the state. In some kinds of nationalism, the state actually helps form and shape the nation drawing on the inheritance of ethnicity as 'raw material', but even this kind of nationalism can evolve into a civic-oriented state, where belonging depends more on citizenship and rights rather than blood and ancestry. Many people in western societies believe that nationalism is rare or marginal in their societies. A useful counter to this is Billig's (1995) study which identifies 'banal nationalism', reminding us that nationalism has been naturalized in many Western settings operating at an almost subliminal level, like background noise, ever present and contradicting the claim that the nationalist age has passed. The ideological habitus that Billig's notion captures enables the reproduction of established nations, within a persisting nationalist framework even as they deny its presence. In an unmarked and naturalized way, nationalism operates to 'indicate' the nation to its citizens, in continual and taken for granted 'little ways', practices and routines of life, governance and social ritual.

For Billig, nationalism is 'the endemic condition' (Billig, 1995, p. 6) and that both ethnic and civic 
dimensions are encountered in all nations. Nations distribute and mobilize symbolic capital, sentimental attachments and value, as well as instrumental benefits. It is to these enduring, indeed in the latter part of the twentieth century resurgent, elements of human collective behaviours that must be allocated consideration along with economic and political rights and benefits of the kinds distributed by civic nationalism.

For much of the twentieth century, modernist thinking has had the upper hand in theorizing about nations and nationalism. It seemed likely that cold war political alignments would bring about the obsolescence for nationalism-based politics; the latter having exhausted itself during the wars of the twentieth century, replaced by the new ideological groupings of blocs, the communist-capitalist world alignments. However, the 1990s has witnessed a re-emergence of nationalist advocacy utilizing language, ethnicity and religious markers of identification. These are as vibrant and persisting as those encountered in any previous era.

In the light of these reformulations, the modernization school can no longer claim to prevail in scholarly discourse, and such post-modern complexities as the simultaneous manifestation of rivalrous nationalisms alongside what can only be considered a steady erosion of nationalist sentiment in other settings. Globalization, regionalization and localization co-occur in complex interdependence and no overarching unidirectional pattern is evident (Giddens, 1999).

In this respect, Benedict Anderson's (1991) examination of nationalism concludes that its sustaining entity is ultimately an imagined community. Unlike traditional notions of community based around daily acts of interdependence the members of even small nations will never experience interpersonal intimacy as a sense of communion with their national co-habitants. Their populations are too large and dispersed and yet such large collectivities live precisely as a community in the imaginings of its members. This idea differs from the modernist approach exemplified in the work of Hobsbawm (1992) and Gellner (1983). For Anderson, the assertion of the realm of ideas, as imagination, in nationalist scholarship is a reaction against an assumption made by modernists that nationalism is somehow false, or primitive, and only a stage of 'high literate culture' in industrial democracies that with the advanced relations of post-industrial economy and technology would be superseded.

Modernist constructions of national community are based instead on conditions of possibility rendered by industrial modernity but these in Anderson's understanding cannot fully explain the question why individuals are willing to die and kill for nations, the answer to which Anderson locates in the 'cultural roots of nationalism' (Anderson, 1991, pp. 6-7).

But Hobsbawm (1992) and Gellner (1983) offer important cautions against nationalism theory unhinged from conditions of economy, society and history. As modernists they stress that the nation is neither a primary nor an 'unchanging' entity, an entity they locate exclusively in a historically recent period. Indeed, for Hobsbawm the national question is situated at the intersection of politics, technology, and social and economic transformations associated with modernity, arguing that standard national languages emerge only with printing, mass literacy and schooling.

This modernism holds that nations are constructed, essentially 'from above' though the nation cannot be understood without reference to the view 'from below'; which is found in the assumptions, hopes, needs and interests of 'ordinary people' (Hobsbawm, 1992).

\section{Language as a component of nationalism}

Fishman (1972) argued that the function of language in nationalism could be understood under three headings: authenticity, unification and efficiency. This means having a shared standard language that is distinctive to the specific national state, that is a 'national' language. 
The authenticity function provides the sense of genuine difference that nations seek from their neighbours and other outsiders. Unification involves the deployment of a distinctive language to make disparate parts of a national population cohere; whether these are regional or social in origin, differences can be minimized by common speech. Efficiency refers to the practices of the vertical structure of state, census taking, public education, delivery of services, military organization. The authenticity function often revolves around a vernacular literature, whose main role is to inculcate newcomers and the young into the community of culture and communication that is the horizontal axis of nationalism. In Anderson's (1991) terms, this authenticity function provides continuity and frequency of reminders and associations and a collection of narratives for national belonging. A growing literature which presents and re-presents common experience is the main operational modality for language authenticity.

In Fishman's (1972) characterization, nationalism is based on and formed by the organized efforts of groups of self-conscious nationals to conserve and transmit to future generations their ethno-cultural distinctiveness. This distinctiveness is often symbolized and at times is actually synonymous with the language of the particular group. For Fishman, nationalism itself is the 'organizationally heightened and elaborated beliefs, attitudes and behaviors of societies acting on behalf of their avowed ethnocultural self interest' (1972, p. 5). This view, so different from that of Hobsbawm and Gellner, links nationalism to a continuation, not a construction, of the past and of a present link with the past, and its destiny into the future, and a link from elites who motivate the nationalism to the masses who in some ways best represent it. Fishman (1972) claims that

It is part of the specific nature of the nationalist ... stress on authenticity to find it in the lower classes and the distant past. This stress on authenticity functions in a complex way as both 'evidence' of continuation from the past and a claim to persistence into the future, both 'science' and 'political program'.

However, there are many states in the world that are clearly based on different nationalisms but that use the same language, such as the 22 Spanish-speaking countries and a similar number that use Arabic. A common and distinctive national language might be a useful resource for nationalism, and often a defining quality of an ethnicity, but it is clearly not sufficient in all cases and in some cases it is not necessary.

The role, therefore, of language in nationalism is located in situated and historical conditions of creation of the specific nation. Blommaert's (1996) study of language in the nationalisms encountered in Flanders and Tanzania highlights how superficial similarities can conceal deep differences. In the complex conditions under which nationalist sentiment is mobilized for political action, language can range from a power to define and give cohesion to identities in search of statehood in which associations are claimed between a language and the 'spirit' or 'soul' of a national group to any number of historically grounded and therefore unique ingredients of the way in which language articulates and sustains nationalist claims. In the nation-building of one experience (Flanders), the distinctive language constitutes the identity marker for its speakers, while in the other, Tanzania, the language (Swahili) is best understood as part of an ideology movement of political democratization and 'socialist strategy'.

\section{European and Australian similarities}

The language policy actions in the EU today reflect several of these strands. The modernist stress on the utility of languages for efficiency of state operations and consolidation of national unities is found in those programmes where literacy is emphasized as an economic necessity for competitive labour markets. The national unifying and authenticity functions are found in two ways, in the stress of the EU 
on the official national languages of the member states being allocated equal status, despite the cost of translation, and interpretation and the claims for a more efficiency based selection of a small number of languages, or of English alone (Phillipson, 2003).

The very contested pathway for the ratification of the 1992 Charter of Regional and Minority Languages shows that languages marginalized in the construction of national states were perceived to be potentially more problematical than fully foreign languages. The latter have been the big success story of EU language planning.

Few states, in the context of economic globalization, fail to recognize the utility of expanded and improved foreign language study, and none see any challenge to national sovereignty or cohesion through extensive individual bilingualism. Minority languages, those with a claim to territory, however, do present either weak challenges to state cohesion, and in these cases attract tolerance or benign neglect, or offer stiffer challenges to national unity, in which case these attract either opposition, or compromise when they achieve state-seceding power.

In all of the above ways, Australia has behaved similarly. Foreign languages with commercial promise, whether real or perceived, have attracted substantial policy support, whereas indigenous and immigrant languages have struggled for commensurate attention in policy and funding. English literacy initiatives and the teaching of English for newcomers have consistently rated the greatest attention in policy and funding (e.g., Moore, 2001; Nicholls, 2001; Ozolins, 2001). These points will now be elaborated in a contrastive discussion of Scotland and Australia.

\section{Language policy texts in post-devolution Scotland}

In 1997, a large majority of Scots voted in favour of a devolution package proposed by the British government of Prime Minister Tony Blair. The result was that the administrative control vested in Scotland, compared to Westminster, expanded in range and depth, and, most importantly, that a directly elected Parliament was established at Edinburgh, the first since the Union of the Parliaments in 1707. The new state, or semi-state, emerging (or re-emerging) from this process provides an important experience of language and nation connections for language planning analysis.

The wider political devolution within the United Kingdom supplies evidence of how implied policy (i.e., policy as a collection of prevailing attitudes) is transformed into explicit and overt policy attention at moments when political jurisdiction more closely aligns with specific linguistic and territorial associations. Although by comparison with other parts of the United Kingdom, Scotland had enjoyed a relatively high degree of administrative autonomy before 1997 since devolution, the 'question' of Scottish Gaelic, and of language policy in general, has repeatedly surfaced for prominent attention.

The context of devolution is evident in the number and range of policy investigations, reports and analyses commissioned by the new Parliament. Among the language issues that have been considered for policy treatment are English (child and adult literacy, English as a second language), British Sign Language, Scots and its regional varieties, Gaelic, immigrant origin community languages, and foreign languages (especially the official languages of the EU of which Scotland, through the United Kingdom, is a constituent part), and non-European foreign languages. Of these issues, concrete progress from discourse to text, and resources, has been easiest for adult literacy and hardest for Scots, most embellished for Gaelic and least productive for modern and community languages. In what follows, some key texts and debates in these areas are discussed before the Australian situation is considered.

A policy on culture

At base, a 'Cultural Strategy' is a policy text for distributing public finance to the arts. Creating our 
Future...Minding our Past, Scotland's National Cultural Strategy (Scottish Executive, 2000a) also devotes considerable attention to identity, language, ethnic pluralism and cultural production, and has made available and legitimated a way 'to discourse' on state, culture and nation in the post-devolution context. The language the Strategy deploys makes 'difference' a central organizing idea: 'This strategy takes a broad view of Scotland's culture' (p. 4), 'everyone contributes' (p. 5), 'Celebrating Scotland's cultural heritage in its full diversity' (p. 23) while making explicit connections between culture and economy via creative industries (Scottish Executive, 2000a). The Strategy lists among its key aims: 'Promoting Scotland's languages as cultural expressions and as means of accessing Scotland's culture' identifies English as 'both asset and threat' in its impact on Scotland's 'other languages and dialects' and on the motivation of Scots to learn other languages (p. 23). The Strategy is very positively disposed towards Gaelic, identifying initiatives for its support, and also for the Scots language, about which it says, 'The Scots language continues to be widely spoken today and has a long and important history' (p. 24). Similarly supportive statements are made for 'other languages'. Within this discourse of celebration of diversity the Strategy is also shaped by a required need for 'practical benefits' that can be seen to derive from the continued active use and transmission of heritage languages, and so it explicitly argues an economic connection for languages.

In effect, Creating our Future ... Minding our Past (Scottish Executive, 2000a) constitutes an authorizing framework for conservation of the linguistic heritage and resources of Scotland and for measures to integrate language diversity into wider state and national objectives and policies. It also offers legitimation for public participation around issues of difference and diversity as unthreatening to the new state, or as constituting the nation that 'surrounds' that emerging new state. In advocacy and in persuasive debate, the Strategy appears to have contributed rhetorical tools and support for community advocates to engage in citizenship-based policy conversations.

\section{Gaelic}

In 1901, 210,677 persons declared that they were regular users of Scottish Gaelic. This represented some 5.2 per cent of the population. One hundred years later, the 2001 census showed that about one-quarter of that figure can speak Gaelic. The 1981 census recorded that 79,307 people, 1.6 per cent of the population, spoke the language, a figure which declined dramatically further in the subsequent 10 years to 65,978 or 1.35 per cent of the national population of 1991 (MacKinnon, 1991; Lo Bianco, 2001a). The census figures reveal three levels of reduction and restriction: decline in absolute numbers of speakers; restriction in the age profile so that fewer younger people acquire Gaelic in their homes; and decline in the proportion of the overall population represented by Gaelic speakers.

The Scottish Parliament has devoted most energy and has reserved its most powerful prose on Gaelic, although action on behalf of the language had occurred prior to devolution, with the major public examination, Cor na Gàidhlig, in 1982, leading to the formation of the organization Comunn na Gaidhlig to supervise initiatives to support the language. The new Parliament appointed a Minister, among whose other responsibilities resides Gaelic, and established the MacPherson Taskforce (Scottish Executive, 2000b) to enquire into the state of the language. The Taskforce report, Revitalising Gaelic: A National Asset, concluded that: 'Gaelic is in a precarious, even critical, condition and ... without significant Government support it will not survive beyond the mid-point of the 21st century'. This request for 'significant Government support' includes what is referred to as 'secure status' (McLeod, 1997), that is legislation that guarantees the juridical prominence of Gaelic as a language of the state, and in the view of some advocates makes available domains of required usage.

In commissioning the MacPherson examination, the then Minister, Alasdair Morrison, in debate in the Scottish Parliament, made the association between Scottish national identity and Gaelic paramount:

Gaelic is a precious jewel in the heart and soul of Scotland. It is not constrained within strict 
boundaries or herded into tight corners. Gaelic is national, European and international. It is fundamental to Scotland; it is not on the periphery or on the fringes. It must be normalised and its rights must be secured. ${ }^{1}$

The language here is personified, a subject as well as an object for policy attention. Illness and fragility are the dominant metaphors deployed to characterize Gaelic in MacPherson described as 'a critically ill patient on life support' and 'It is hanging on by a thread which is getting more frayed by the day. Despite occasional signs of remission, the prognosis is bleak' and describing its historical treatment graphically:

The history of the Gaelic language has been a chronicle of dereliction: official negligence; malicious intent; deliberate denial; and, perhaps most damaging of all, benign neglect. The language has suffered from stigmatisation and from attrition through outward migration, loss of population and decline of community.

It also commented on public imagery

that the Gaels do not have their act together, that resources are being duplicated, and that public money is not being prudently apportioned or spent. While much of the 'Gaelic debate' is candid, open and healthy it occasionally generates more heat than light and the rhetoric sometimes assumes greater importance than the language itself.

In response to MacPherson, a further grouping was convened, the Ministerial Advisory Group on Gaelic that in turn reported in May 2002 (Scottish Executive, 2002) the Meek Report. This report, $A$ Fresh Start for Gaelic, proposes a series of measures in keeping with the broad approach of MacPherson, focused on immediate action on a Gaelic Language Act 'to establish secure status for the language' and the creation of a new Gaelic Development Agency with national powers to require public-sector bodies to collaborate in supporting Gaelic, research and funding; the provision of a National Plan for Gaelic, combining strategic priorities, key actions, targeted research, and a call for a National Policy for Gaelic to be prepared by February 2003. The key areas of action contained in $A$ Fresh Start for Gaelic are language planning, education and learning, culture and the arts, and economic and social development.

The reports, MacPherson and Meek, are impressive in organizational and planning coherence, in consistency and sophistication of analysis and also in sober and serious assessment of the prospects of success. They are also impressive rhetorically, making available to the public, both the immediate interest groups, and others, even hostile others, ways to constitute Gaelic's role in the emergent polity.

The authorizing remit for this intensive period of heritage language planning is the Programme of Government that followed devolution and which commits Scotland to intervene to support the revitalization of Scottish Gaelic. Contained in Revitalising Gaelic: A National Asset is a discourse that seeks to express the vision driving these efforts:

a foundation-stone in the building of the new Scotland, the Gaelic language will be an integral and dynamic component of a self- assured community with economic and social stability and pride in its linguistic and cultural identity.

Work on behalf of Gaelic occurs in concrete community level regeneration activity, in schools, media, culture and industry (McLeod, 1998), as well as in the policy discourses. There has been considerable success in some areas of revitalization. Whereas in 1984, there were probably no students undertaking a Gaelic-medium education, by 1999 some 1850 pupils were enrolled in such programmes. This success in primary schooling has echoes in other education sectors. In 2000 the first-ever graduates in Gaelic-medium higher education took degrees from Sabhal Mór Ostaig, through 
the Open University. Also in 2000 the first full Gaelic-medium school (primary level) commenced operations in Glasgow, and Gaelic-medium secondary units are planned. Success has also been achieved in broadcasting, both radio and television (Lo Bianco, 2001a).

Metaphoric characterization of Gaelic as ill, potentially moribund and its recuperation constituted as essential to national integrity reveals an energetic desire to attach state and nation making civic identity functions to Gaelic. But these functions are dominated by English, and claimed also by Scots, and even by some immigrant minority activism. It is too early to see what response there will be to the Meek Report's formulation of the way forward but it seems clear that many of the initiatives will proceed. The interconnection of rhetorical policy making (how it marshals strategically discourses of extreme urgency, of national integrity, of identity and connection with the past) with organizational routines of elaborating plans, organizing intervention and deploying resources demonstrate that to understand policy in language is to see the language of policy making as an essential component of the overall activity.

\section{Scots}

For Scots, both the action and the prose are missing (Scott, 1998). Thus far the Scottish Executive has not produced any major policy-related documentation for the Scots language of a sort that would compare with MacPherson and Meek for Gaelic, or with Mulgrew (see below) for modern languages, or with the activity on behalf of British Sign Language, or on adult literacy. Moreover, the amount of national funding directed to the Scots language, mainly through the Scottish Arts Council, is minute in comparison to what is provided nationally for Gaelic, for modern languages through schooling, indeed for any identifiable language category. There has been a refusal thus far to have Scots language signage in the Parliament to accompany existing English and Gaelic signs.

Scots advocacy devotes considerable time at meetings, and conferences, responding to questions about whether Scots is a separate language, or 'just a dialect', that is 'English without the Norman invasion'. Often the discursive effect is to erode seriousness of purpose and mobilization. Some advocates even position themselves this way, anticipating such questioning and answering it in advance. The effect, sometimes, is to divert attention into a definitional netherworld damaging to credibility and making social claims vulnerable to marginalization.

However, the new Parliament may have instigated a move forwards, making possible a future policy conversation on Scots in the deliberations of a cross-party grouping of interested Parliamentarians that meets with representatives from the Scots language community. The transfer from community to Parliament, two talking orders differentiated by their capability of resource disbursement, of a mandate to commission formal investigative texts on Scots holds promise that devolution may yet produce language planning for Scots too. A new and different discourse would surely result, given that Scots is more readily associated with separatist Scottish nationalism than Gaelic, much less restricted geographically, being mostly urban based, widely used, and prominent in many academic institutions. Although Scots encounters problems of representation that are unique to its status as a cognate of English, its discursive representations will not need to draw on ill health and medicalization, but will need to deploy state-attention commanding power as a mostly well and thriving a repertoire of spoken varieties, with a burgeoning literature, and a distinctive association with the new state.

\section{Adult literacy}

Devolution resulted in overlapping responsibilities in adult education and so unlike other fields in which the new Parliament has had a clear remit for action, adult training, and economic and labour market planning is shared with Westminster, requiring UK-wide negotiation. Despite this, adult literacy is perhaps the single most effective language policy activity undertaken since devolution, in which the 'flow-through' between an initial policy investigation process, subsequent policy determination, and resource allocation and programme implementation has been very fast. The whole process has manifested a more transactional or propositional language, less persuasive and rhetorical, more 
reflective of the business-like approach of public administration, with most talk about economy, and social inequality, all tied closely to existing government meta-policy, or ideologies, which has been a key feature of the energetic policy moves in from 1999 to 2001.

The problems that policy advocacy put forward for action used staple talk of economic transformation under globalization, the 'knowledge- basis' of production and the resultant labour market demands, the declining occupational prospects for older workers under these changes, and the serious social, economic and health consequences for the young with literacy difficulties. This is a potent mixture that aligned the mainstream and expected language of contemporary governance with professional advocacy for literacy provision. The result is a series of funded, publicly supported initiatives governed by an overall policy of provision and review.

The importance of literacy, print and working in globalizing economies occupies education everywhere since most education and training systems operate within a framework that sees education as investment in human capital (OECD, 1998). Adult literacy, therefore, is a kind of mainstream language planning, in Scotland as elsewhere, working within parameters shaped by existing government priority, even if challenged by some practitioners, researchers and minority language communities (Hamilton et al., 2001).

Shared assumptions about human capital, the technical economy and literacy in Standard English provided space for prevailing ideologies and attitudes on languages to function as default language policy, but this reveals the officially sanctioned hierarchy among languages. While most literacy action utilizes English there are considerable consequences for Scots speakers (Addison, 2001), but these have been mostly ignored, and there has been virtually no attention to other minority language literacy.

\section{Modern languages}

In school languages education, as in adult literacy (but without its conspicuous success), the new Parliament has also been active. First, a 1999 report by Her Majesty's Inspectorate, Standards and Quality in Primary and Secondary Schools 1994-1998: Modern Languages, and then a full-scale Ministerial investigation, the Action Group for Languages (Scottish Executive, 2000c) - the Mulgrew Report indicate the effort devoted to the field.

Although the proportion of students taking languages is greater than in England (Nuffield, 2000), the range of languages offered is narrower, mostly the official EU languages, predominantly French, some German, less Spanish and Italian, and some community languages, Urdu and Chinese mainly (Powney et al., 1998).

The Mulgrew Report deploys a rationale for languages which seeks to go beyond 'conventional reasons' to associate the case for an enhanced place in Scottish education with 'the major changes ... sweeping across Scottish and international society'. These changes are noted as: European mobility, social inclusion, citizenship and democracy, the 'age of information', cultural diversity and the 'evolving identity' of Scotland. In a series of arguments, the Report addresses economic regeneration of Scotland and benefits for individual learners. The recommendations of Mulgrew centre on the proposal that all students should be entitled to an experience of learning a modern language that is continuous, serious and widely esteemed, and that heritage and community languages, including Scottish Gaelic, feature prominently. Since its release, the report has become mired in wider administrative changes, devolution to local areas, and its overall policy goals retarded in implementation. Its aim of diversification of offerings away from mostly French appears unlikely to succeed, and its attempt to recruit a discourse of economy, citizenship, European integration and Scotland's global connections to a reinvigorated interest for languages in general seems equally challenged. 
In launching the report, the Minister for Education, Europe and External Affairs drew attention to the need for continual improvements in the quality of teaching and learning of languages commenting that the EU constitutes a kind of inevitable internationalization for Scotland, and an internationalization in which effective multilingual proficiency will be prominent (McConnell, 2000). But the wider educational devolution to local authorities has depleted the case for modern and community languages at a national level, and deprived the review of a place in the national conversation about the future of Scotland and its identity. Worst affected are heritage languages without claims to place, to territory and to ancestral history and the languages of recent immigration. Thus far, the arguments mounted for these languages succeed best when connected to enhanced educational outcomes for specific groups of learners, and, though to a lesser extent, to a discourse of stemming the waste of potential linguistic proficiency, the skills of language competence that minority language speakers donate to their new community.

\section{British Sign Language}

An important debate on issues concerned with deafness and the rights and opportunities of deaf Scots took place in the Scottish Parliament on 16 February 2000 (see Lo Bianco, 2001a). Some speakers suggested that British Sign Language (BSL) is an ancient heritage of the nation; others talked about the issue in terms of needed action to deliver public services more effectively; others spoke of social inclusion, or welfare, opportunity and rights.

Users of BSL number some $1,00,000$ though this is likely to be a considerable underestimate given the use of BSL by hearing members of the families of deaf people, friends and professional workers as well. According to calculations conducted by the Royal National Institute for Deaf People, about one in seven persons in the United Kingdom have hearing loss. This is highly variable as to extent and time of onset. One in seven persons would result in well over 8 million people, over half probably being over the age of 60 . Given the accelerated rate of ageing, it is likely that the number will grow proportionately over the coming decades; the profoundly deaf number about $7,00,000$, of whom about three-quarters are unable to use a voice telephone.

Sign language users everywhere, it seems, have had to endure a long struggle against misunderstanding, misrepresentation and repression. The educational dimension of such misunderstanding and repression is longstanding and international. Often it takes the form of the oralmanual controversy, with oralists advocating the exclusive use of speech and the related suppression of Signing while manualists encourage Signing, sometimes combined with or accompanied by speech. Oralism reached its height of international prominence in 1880 at the Second International Congress of the Education of the Deaf with the adoption of a resolution that held the 'incontestable superiority of speech over Signing' (Lo Bianco, 2001a). This led to the adoption of oral methods across Europe that predominated for many decades afterwards.

The survival of BSL in the face of such strong assimilative pressures recalls struggles of other language minority groups for recognition of linguistic legitimacy in societies of which they are an integral part. BSL users are a community with a history of struggle for recognition as a component group of society, a distinctive community culture, and therefore a heritage language community.

As the Parliament's speakers reflected, BSL advocacy contains a similar range of discursive representations as for other heritage languages: from positions that stress community and ethnicity, its distinctive modes of expression, and identity; to others that locate the issue within welfarist understanding, some which medicalize deafness, and some which are dismissive and rejecting of culture and community based representations. In addition, policy discussions about deafness and sign language are rarely constructed as language planning or as cultural and citizenship entitlements, for sign language users. The Parliament, as an expression of the post-devolution effort towards citizenship representation, has made Signing an issue of language rights, as well as social 
opportunity, but appears still to be seeking a principled way to integrate this perspective into the array of other representations that jostle for prominence.

\section{Europe}

European integration is found most concretely in its human mobility entitlements. It is a right of all citizens of the EU to seek employment, education or recreational and residential opportunities across the Union. In a 1995 policy, the European Commission set the objective of all EU citizens being proficient in three European languages. It stated:

Proficiency in several Community Languages has become a precondition if citizens of the European Union are to benefit from the occupational and personal opportunities open to them in the border-free single market. This language proficiency must be backed up by the ability to adapt to working and living environments characterized by different cultures.

(European Commission, 1995a, p. 67)

These provisions were strengthened in 2001 removing the specification that the languages should be official languages of member states.

The Convention on Regional and Minority Languages has, by contrast with the learning of official state languages, or of any foreign language, encountered a slower, more contested, path. Despite being adopted in 1992 by the EU, it was only signed into law by the UK Government in March 2000 and ratified in July 2001. The convention makes specific mention of both Scottish Gaelic and Scots. The specific consequence is required provision of Gaelic in certain defined civil proceedings in geographic areas of Scotland where Gaelic speakers dominate.

Regular assessments of the 'state of Europe' through a series of Euro-barometer studies between 1994 and 1996 reflect the social distribution of bilingual skills. While age and occupation are the best predictors of conversational proficiency in an additional language, the strongest predictor of low spread of bilingualism is having English as the official or national language of the country. In Englishspeaking countries, the distribution of bilingualism shows it to be the province of recent immigrants, indigenous communities with intergenerational language vitality, language professionals and enthusiasts (Table 5.2).

The situation in Scotland was introduced as reflecting a new state within an old nation. Its purpose has been to highlight the modernism of new states, and this is clear from the fact that pragmatic and economic connections in some language issues, such as adult literacy, prevail in achieving policy success, but the state deploys strong rhetorical affirmation of its national (but weakening) language. Within the context of the EU's actions, Scotland is an exemplary case - it is an old nation and therefore nationalist discourse prevails for its indigenous and distinctive language; it is a new state, and so the stress on efficiency and unification tends to favour literacy, adult literacy and discourses of economic competitiveness. Fishman's principles of authenticity (directed towards Scottish Gaelic), efficiency (adult literacy, English, strategic foreign languages) and unification (concerns about Scots, about community languages) are all in evidence. However, these play out in a specific instance, a precise moment in history, and a point of intersection between state and nation. As the issues arise at these historicized junctures, the specific effects of policy are influenced by local and temporal contingencies; this means that what actually occurs in policy, its effects, can be ambiguous and only situated 
Table 5.2 Selected demographic variables and bilingualism (\%)

\begin{tabular}{ll}
\hline Socio-demographic category & Bilingual (\%) \\
\hline Students & 77 \\
Educated up to 20+ & 72 \\
Managers & 69 \\
Aged 15-24 & 65 \\
Employees & 57 \\
Aged 25-39 & 55 \\
Self-employed & 50 \\
Men & 47 \\
Average for EU 15 & 45 \\
Educated to age 16-19 & 44 \\
Aged 40-54 & 43 \\
Women & 43 \\
Manual workers & 41 \\
Unemployed & 40 \\
House persons & 31 \\
Aged 55+ & 28 \\
Retired & 26 \\
Educated to age 15 or younger & 19 \\
\hline
\end{tabular}

Sources: European Commission 1995b, 1997

accounts of their emergence can account for precise policy effects. These can change the specific ways in which language pluralism is debated and what policies are enunciated. This sense of the local and the time bound is further reinforced in the next section, which discusses Australia.

\section{Ambiguity and tension in Australian language planning}

\section{Australia: Linguistic demography}

Australia is very often cited in the international literature as an excellent example of a country that has pursued language policy making energetically. Fishman (1991) and Tollefson (1991) are only two examples. Australia is indeed remarkable for the number and frequency of the language policy statements that its Federal and state governments have issued (Lo Bianco, 2001a,b). This section describes something of the number and range of languages in Australia and then considers the policy framework and sequence of Federal government statements against the above discussion of nationalism and statehood, with specific attention to the discourses surrounding minority languages. 
Table 5.3 Australia's Linguistic Diversity

\begin{tabular}{ll}
\hline Community & Foreign \\
\hline Indigenous & Asian \\
Regular teaching: possibly $\sim 10$ & Principally Chinese, Indonesian \\
$\begin{array}{l}\text { Revival: potentially } \sim 50 \\
\text { Revitalization: potentially } \sim 100\end{array}$ & Korean and Japan \\
Renewal: all & \\
& \\
Immigrant & European \\
Potentially well over 100 languages & Principally French, German and Italian, but also \\
& Russian and Spanish \\
\hline
\end{tabular}

Australia's linguistic demography can be divided into two very broad categories: community (heritage) and foreign languages (Table 5.3). Community languages further subdivide as indigenous and immigrant, and the foreign languages as Asian and European.

\section{National policies}

In 1984 the Senate of the Parliament of Australia concluded a 2-year investigation into whether it was in the national interest to develop a nationally coordinated approach to language policy. Its primary recommendation was in favour of national language planning, and especially the developing and promulgating of comprehensive (addressing all of Australia's language and literacy needs) and collaborative (engaging all jurisdictions as well as community level non-government structures and agencies) policy. In response, a policy investigation was commissioned in late 1986 and, after extensive national consultations, was issued publicly and formally adopted by Cabinet as The National Policy on Languages (NPL) on 4 June 1987.

State and Territory governments adopted the guiding principles and argumentation of the NPL and evolved state level policies, structures and programmes in keeping with the national framework. The result was a coherent national system of planning.

Since that time there has been a massive expansion in language teaching and learning at all levels of education and training though there are regional variations acknowledging differences in demography, starting levels and subsequent modifications. Although variable across the country there are also now relatively coherent systems of collaboration between public and community providers of language education.

The overarching justifications of the NPL were expressed as four Es:

1. Enrichment: representing intellectual and cultural enrichment, for individuals and for the wider society.

2. Economics: facilitating trade and commercial relations, with a special emphasis on the Asian region, but not neglecting Europe and other parts of the world.

3. Equality: representing enhanced social and educational participation and opportunity for immigrant and indigenous communities and for speakers of non-standard varieties of English as well as for users of Australian Sign Language and for those students with language disabilities.

4. External: facilitating strategic responses to diplomatic, commercial and security interests.

The principles of the NPL are summarized as follows and elaborated into very broad programme categories (Table 5.4). 
Table 5.4 Overview of the National Policy on Languages

\begin{tabular}{|c|c|c|}
\hline English & Standard Australian & $\begin{array}{l}\text { ESL for adults and children } \\
\text { ESD for adults and children } \\
\text { Literacy for adults and children }\end{array}$ \\
\hline Languages other than English & $\begin{array}{l}\text { Immigrant, foreign and Australian } \\
\text { Sign Language }\end{array}$ & $\begin{array}{l}\text { Language maintenance and } \\
\text { second- and foreign-language } \\
\text { learning }\end{array}$ \\
\hline Indigenous languages & $\begin{array}{l}\text { Aboriginal and Torres Straight } \\
\text { Islander languages; both spoken } \\
\text { and lost }\end{array}$ & $\begin{array}{l}\text { Language maintenance } \\
\text { Renewal, revival and revitalization }\end{array}$ \\
\hline Language services & $\begin{array}{l}\text { Interpreting and translating } \\
\text { Policy-related research } \\
\text { Libraries, broadcasting } \\
\text { National coordination and policy } \\
\text { review }\end{array}$ & $\begin{array}{l}\text { Widespread, equitable and } \\
\text { professional language services }\end{array}$ \\
\hline
\end{tabular}

The actual principles can be summarized as:

- That all Australians gain high levels of literate standard Australian English.

- That all Australians achieve bilingualism, either by maintaining languages other than English as they acquire English as a second language, or by adding second languages to their existing English.

- That indigenous and islander languages will be acknowledged as a unique and irreplaceable heritage of Australia and energetic efforts will be made to preserve, restore and secure these languages.

- That equitable and widespread professional language services will be encouraged.

Based on these principles, elaborated into a large number of coordinated programmes, the policy involved a set of actions aimed at producing English-plus multilingualism, removing language-based social inequalities and discrimination, and enhancing public esteem for bilingual competence.

In 1991, the policy reauthorization process brought about some modifications to the style, and priorities of the NPL, though the principles remained essentially unchanged. In 1994 a special acceleration of the educational efforts for four key Asian languages was initiated (Table 5.5).

It is stressed that only the first policy report (NPL) in Table 5.5 is a comprehensive national language plan, extending across all of government and into civil society. The second (ALLP) focuses only on Federal education and training provisions. The third (NALSAS) ${ }^{4}$ accelerates action on behalf of four languages in education and training. These are listed, therefore, in descending order of comprehensiveness as policy statements on language and literacy.

As far as education is concerned, the NPL was based on the formula of: Community Languages plus nine key languages (Arabic, Chinese, French, German, Greek, Indonesian-Malay, Italian, Japanese, Spanish) plus indigenous languages. The ALLP nominated 14 languages (one of which was all indigenous languages, the nine key languages and some others, but it stressed the priority of English literacy), the COAG addressed only four languages to accelerate the rate of their expansion in education. 
Table 5.5 National policy commitments to education in languages other than English

\begin{tabular}{|lll|}
\hline $\begin{array}{l}\text { National Policy on Languages (Lo } \\
\text { Bianco, 1987) }\end{array}$ & $\begin{array}{l}\text { Australian Language and } \\
\text { Literacy Policy (ALLP) } \\
\text { (Dawkins, 1991) }\end{array}$ & $\begin{array}{l}\text { National Asian Languages } \\
\text { and Literacy Policy (NALSAS) } \\
\text { (COAG, 1994) }\end{array}$ \\
\hline $\begin{array}{l}\text { Community } \\
\text { Languages (Auslan) }\end{array}$ & $\begin{array}{l}\text { Reduced Community } \\
\text { Languages (Cls) }\end{array}$ & $\begin{array}{l}\text { Chinese (Mandarin) } \\
\text { Japanese }\end{array}$ \\
'Key Languages' & $\begin{array}{l}\text { Stressed Foreign Languages } \\
\text { (Fls) } \\
\text { English literacy } \\
\text { Trade languages }\end{array}$ & Indonesian \\
\hline
\end{tabular}

These many policy moves indicate an active sequence of nationalism and national identity debates in language policy (Lo Bianco, 2004). Those that relate to conceiving first-language maintenance for immigrants as something the state could envision, the community languages movement, and the Asian languages movement that brought forth new discourses of identity and participation that were pluralist and civic, made possible 'heritage talk' in relation to languages.

In Australia, policy agitation for heritage languages has always been conducted under the term 'community languages'. This term was used to distinguish immigrant and indigenous languages from foreign and classical languages and to suggest that locally used languages should have priority, or at least equality, of esteem. This was all part of an emerging, and ultimately successful, discursive politics that linked pluralism to the state, eventually becoming a shared political project of all mainstream political parties. Australian bilingual education, which had enjoyed a flourishing nineteenth-century history (Clyne, 1991) had fallen victim to a 1917 cultural policy that withdrew Australian identity within Empire and English.

In 1973, for the first time since 1917, Australian primary schools started to teach languages. Until then, what had survived First World War language policy, save small exceptions, were elite foreign European languages, taught not for speaking and using, but for writing and reading, and, in fact, taught for the purposes of selection into higher education (see Chapter 1). But in 1968, institutional changes removed the requirement for language study as a criterion for university entry. The result was a collapse in numbers. By the mid-1970s, schools were expected to get close to their communities, many of the communities were multilingual and newly confident and citizens. Heritage language advocacy became prominent, but the term 'community language' was, and is, preferred, given the continuing vitality of many of the languages. Inserted into policy discourses was new imagery about national multilingualism.

Through the active process of policy writing from the 1980s and 1990s, until the beginning in 1997 of concern for standards of English literacy and progressively less stress on languages other than English, Australia was beginning to evolve a sense of nationality that was compatible with multilingualism. This has now dissipated and it remains to be seen whether the new supra-national entity of Europe will open new possibilities for multilingual planning and its inherent new sense of nationality and post-nationality for Australia.

\section{Concluding remarks}

Contrasting Australian and European discourses in relation to minority language policy provision 
reveals the complexity of policy action due to the radically different juridical and socio-political contexts that prevail. However, when we contrast and compare a new state for an old nation in the case of Scotland, and a new state in Australia built on the negation of ancient nationality of the indigenous dispossessed, it becomes clear that principles of statehood and nationality function in relatively consistent ways. Australian policy work reveals a deep Europeanization in its sense of the inefficiency and problematic status of multilingualism, but this is ameliorated by the pragmatic impact of multicultural electoral politics. Asian regional integration and the potential for political mobilization around pluralist notions of citizenship. The Scottish example reinforces this sense that the conditions of possibility for inscribing multilingualism within national policy exist in contemporary societies. Specific historical and situational factors attenuate or promote what kinds of accommodation occur at particular moments and how these can be reinforced or reversed. Language policy is always intimately connected with broader economic and socio-political arrangements, and nationalism theory can be a powerful informing discipline.

\section{Notes}

1. Page references were unavailable for quotes relating to the Macpherson, Meek and Mulgrew Reports.

2. J.S. Dawkins was Federal Minister for Employment, Education and Training.

3. COAG is the Council of Australian Governments. It aggregates the Federal (Commonwealth) government through the Prime Minister and relevant Ministers, and the State and Territory governments through Premiers and relevant State Ministers. NALSAS funding is to terminate at the end of 2002.

4. NALSAS was based on the principle that there should be a $60 / 40$ distribution of language study between Asian and European languages, with a specific acceleration of effort on behalf of the nominated four priority languages. Not all states endorsed the $60 / 40$ formula.

\section{References}

Addison, A.F.P. (2001) 'Using Scots literacy in family literacy work'. In J. Crowther, M. Hamilton and L. Tett (eds), pp. 155-65.

Anderson, B. (1991) Imagined Communities, Reflections on the Origin and Spread of Nationalism. Verso: London.

Billig, M. (1995) Banal Nationalism. Sage: London.

Blommaert, J. (1996) 'Language and nationalism, comparing Flanders and Tanzania', Nations and Nationalism, 2, 2: 235-56.

Clyne, M.G. (1991) Community Languages: The Australian Experience. Cambridge University Press: Melbourne.

COAG (1994) National Asian Languages and Studies in Australian Schools Strategy. Government of Queensland Printer: Brisbane.

Crowther, J., Hamilton, M. and Tett, L. (2001) (eds) Powerful Literacies. National Organisation for Adult Learning: Leicester.

Dawkins, J. (1991) Australia's Language: The Australian Language and Literacy Policy. Australian Government Publishing Service: Canberra.

Enloe, C.H. (1981) 'The growth of the state and ethnic mobilisation: The American experience', Ethnic and Racial Studies, 4, 2: 123-36.

European Commission (1995a) White Paper on Education and Training - Teaching and Learning Towards the Learning Society. European Union: Brussels, COM (95) 590.

European Commission (1995b) Education across the EU 1993/4. Eurostat, Office for the Official Publications of the European Communities: Luxembourg.

European Commission (1997) Key Data on Education in Europe 1997. Office for the Official Publications of the European Communities: Luxembourg.

Fishman, J.A. (1972) Language and Nationalism. Newbury House: Rowley, MA.

Fishman, J.A. (1991) Reversing Language Shift. Multilingual Matters: Clevedon. Gellner, E. (1983) Nations and Nationalism. Blackwell: Oxford. 
Giddens, A. (1999) Runaway World. Profile: London.

Greenfeld, L. (1992) Nationalism: Five Roads to Modernity. Harvard University Press: Cambridge.

Hamilton, M., MaCrae, C. and Tett, L. (2001) 'The policy context'. In J. Crowther et al. (eds), pp. 2342.

Hastings, A. (1997) The Construction of Nationhood: Ethnicity, Religion and Nationalism. Cambridge University Press: Cambridge.

Hobsbawm, E.J. (1992) Nations and Nationalism since 1780, Programme, Myth, Reality (2nd revised edn). Canto: Cambridge.

Lo Bianco, J. (1987) National Policy on Languages. Australian Government Publishing Service: Canberra.

Lo Bianco, J. (2001a) Language and Literacy Planning in Scotland. Scottish Centre for Information on Language Teaching: University of Stirling.

Lo Bianco, J. (2001b) 'From policy to anti-policy, how fear of language rights took policymaking out of community hands'. In J. Lo Bianco and R. Wickert (eds), pp. 11-45.

Lo Bianco, J. (2004) 'A site for debate, negotiation and contest of national identity: Language policy in Australia'. In Guide for the Development of Language Education Policies in Europe, From Linguistic Diversity to Plurilingual Education. Council of Europe: Strasbourg.

Lo Bianco, J. and Wickert, R. (eds) (2001) Australian Policy Activism in Language and Literacy. Language Australia Publications: Melbourne.

Mackinnon, K. (1991) 'Language-retreat and regeneration in the present-day Scottish Gaidhealtachd'. In C.H. Williams (ed.) Linguistic Minorities, Society and Territory. Multilingual Matters: Clevedon, pp. 121-49.

McConnell, J. (2000) McConnell outlines support for languages, 12 December 2000, Scottish Executive Press Releases: Edinburgh.

McLeod, W. (1997) 'Official status for Gaelic. Prospects and problems'. Scottish Affairs, 21: 95-118.

McLeod, W. (1998) 'Scotland's languages in Scotland's parliament'. Scottish Affairs, 24: 68-82.

Moore, H. (2001) 'Although it wasn't broken, it certainly was fixed'. In J. Lo Bianco and R. Wickert (eds) Interventions in the Australian Adult Migrant English Program 1991-1996, pp. 93-121.

Nicholls, C. (2001) 'Reconciled to what?' In J. Lo Bianco and R. Wickert (eds) Reconciliation and the Northern Territory's Bilingual Education Program, 1973-1998, pp. 325-43.

Nuffield (2000) Languages: The Next Generation, The Final Report and Recommendations of the Nuffield Languages Inquiry. The Nuffield Foundation: London.

OECD (1998) Human Capital Investment, an International Comparison. Organization for Economic Co-Operation and Development: Paris.

Ozolins, U. (2001) 'Inventiveness and regression'. In J. Lo Bianco and R. Wickert (eds) Interpreting / Translating and the Vicissitudes of Australian Language Policy, pp. 255-79.

Phillipson, R. (2003) English-only Europe? Routledge: London.

Powney, J., McPake, J., Hall, S. and Lyall, L. (1998) Education of Minority Ethnic Groups in Scotland, a Review of Research. The Scottish Council for Research in Education: Edinburgh.

Scott, P.H. (1998) 'Review essay: The future of the Scots language'. Scottish Affairs, 24: 83-97.

Scottish Executive (2000a) Creating our Future ... Minding our Past, Scotland's National Cultural Strategy. Scottish Executive: Edinburgh.

Scottish Executive (2000b) Revitalising Gaelic: A National Asset (Macpherson Report of the Taskforce on Public Funding of Gaelic). Scottish Executive: Edinburgh.

Scottish Executive (2000c) Citizens of a Multilingual World, Ministerial Action Group on Languages (Mulgrew Report). Tacita Solutions: Edinburgh.

Scottish Executive (2002) A Fresh Start for Gaelic, Report by the Ministerial Advisory Group on Gaelic (Chaired by Donald E. Meek). Scottish Executive: Edinburgh.

Tollefson, J.W. (1991) Planning Language Planning Inequality: Language Policy in the Community. Longman: London and New York. 